\title{
Photovoltaic Stand-Alone Power Generation System with Multilevel Inverter
}

\author{
M. I. Desconzi, R. C. Beltrame, C. Rech, L. Schuch, and H. L. Hey \\ Power Electronics and Control Research Group, Federal University of Santa Maria \\ 97105-900, Santa Maria, RS, BRAZIL \\ Phone number: +55 55 32208463, e-mail: matheusiensen@gmail.com, heliohey@gmail.com
}

\begin{abstract}
This paper proposes a decentralized stand-alone photovoltaic (PV) system, which presents a set of advantages when compared to conventional stand-alone PV system. In the proposed system, the generated energy by the PV arrays is processed by multi-string MPPT step-up converters, which assure a maximum utilization of this energy. The storage system is designed in a decentralized configuration, enabling to achieve a reduction of maintenance cost of back-up system. Moreover, the output stage is composed by a multilevel dc-ac inverter, which enables higher efficiency, low distortion ac waveforms, low leakage currents and the use of low voltage rating semiconductor devices.
\end{abstract}

\section{Key words}

Photovoltaic (PV) systems, multi-string systems, multilevel inverters, stand-alone, battery converters.

\section{Introduction}

The continuous economic development of many countries and the environmental issues (gas emissions and the green house effect) observed in the last decades forced an intense research in renewable energy sources. Hydro, photovoltaic (PV) and wind energy conversion are the most explored technologies due to their considerable advantages [1]-[2], such as reliability, reasonable installation and energy production costs, low environmental impact, capability to support microgrid systems and to connect to the electric grid [3]. Among these energy sources the PV is pointed out as one of the most modular and environmentally friendly technologies. Therefore, PV systems have been frequently adopted worldwide, presenting a growth of $45 \%$ on the total PV power installed in 2009 [4] (the largest growth among the renewable energy sources).

With the continuous improvement on the energy sector, an important situation should be brought out: approximately 1.4 billion people have no access to electricity worldwide [5], which a substantial fraction refers to communities distant from the electric grid. This feature makes the standalone system an interesting alternative for enabling electricity access for those people, and also for remote applications. This way, it is expected that the number of installed stand-alone systems should increase in the next years. Differently from the grid-connected systems, the stand-alone systems demand a back-up system (usually a battery bank and a charger/discharger converter) to supply the load during periods with low or no energy generated. It was demonstrated in [6] that the maintenance costs related to the batteries represent $46 \%$ of the overall PV system cost due to the batteries short lifetime. Thus, it is essential to optimize the back-up system lifetime.

However, it is well know that the PV technology has some disadvantages such as high installation cost, intermittence on the energy production, low efficiency (5-16\%) and requests converters for energy conversion (dc-to-ac) in order to feed the load. Additionally, due to the non-linear characteristics of the PV panel it is required a maximum power point tracking (MPPT) algorithm, usually implemented on the dc-dc or dc-ac stage. Another drawback is the unequal power produced between the PV panels caused by several reasons, such as dissimilarities of panel production, different temperatures and irradiations due to the orientation of the panels, aging and shading.

Therefore, it is imperative that the overall system must present high efficiency in order to make the employment of this energy source economically feasible and costeffective. The former topologies were based on the centralized systems, where a single dc-ac stage manages long string arrays power production [7],[8]. However, these topologies reduce the overall efficiency due to lost of the maximum power point in some occasions. This way, to minimize these problems the decentralized PV systems were proposed, such as the multi-string systems, where the MPPT is divided into several dc-dc stages (usually step-up) and each one dedicated to a short PV string, ensuring the maximum power production.

Concerning the dc-ac stage energy processing, the multilevel inverters have been reported as a possible solution for PV systems [3], with several inherent benefits, such as high efficiency, low distortion ac waveforms and low leakage currents. Additionally, in high power applications the ac power can be synthesized from several low-level cells, i.e., low voltage semiconductors could be employed. The multilevel inverters are also suitable for multi-string topologies, where each string can be connected to the multilevel cells. 
Therefore, this paper proposes a stand-alone PV system based on the multi-string topology that employs a multilevel output inverter. The first stage is composed by a set of dc-dc converters (with MPPT algorithm), and the second stage combines all outputs of the first stage into the multilevel inverter. Furthermore, aiming to optimize the backup system lifetime, a decentralized battery system performing a controlled charge/discharge method is presented.

\section{Proposed Stand-Alone PV System}

The proposed structure, depicted in Fig. 1(a), can be classified as a multi-string configuration, where the first stage is composed by " $n$ " dc-dc converters connected to its correspondent PV string. Each dc-dc converter output is connected to a multilevel cell, performing the dc-ac stage. The back-up system is divided into " $n$ " dc-dc battery converters (Decentralized Battery Converters - DBC) managing a small set of batteries, also connected at the output of the first stage. The arrangement composed by one PV string, one dc-dc converter, one battery converter and one multilevel cell will be considered a module of the system.

The dc-dc converters of the first stage must track the maximum power point of the PV panels. In order to perform this task, step-up/step-down converters are usually chosen. However, in the proposed structure, the choice of the converter will depend on the voltage level of the dc bus, calculated by means of (1),

$$
V_{b u s}=\frac{V_{m}}{n_{s t r}},
$$

where $V_{\text {bus }}$ is the voltage level of the dc bus, $V_{m}$ is the maximum voltage for implementing a desired sinusoidal output voltage and $n_{s t r}$ is the number of strings/modules. The maximum voltage, $V_{m}$, is usually defined as $200 \mathrm{~V}(400 \mathrm{~V})$ for synthesizing an output voltage of $110 \mathrm{~V}_{\mathrm{rms}}\left(220 \mathrm{~V}_{\mathrm{rms}}\right)$.

Thus, if the input voltage of each module (PV string voltage) is higher than $V_{\text {bus }}$, a step-down converter should be employed. Otherwise, a step-up converter is the appropriated choice.

In [9] it was developed a decentralized system for standalone applications, as seen in Fig. 1(b), with the first stage similar to the proposed structure. However, the second stage is composed by a series connection of all dc-dc converter outputs, implementing the dc bus, and an inverter that generates the output sinusoidal waveform. Furthermore, a single converter managing a single battery bank (Centralized Battery Converter - CBC), is connected at the output of the first stage.

Although the DBC system increases the number of semiconductor devices, it is possible to perform a proper charge/discharge method on the batteries. Converters with battery system integrated on the dc-dc stage have been proposed in the literature [10]-[11] aiming to improve the efficiency of the overall system by eliminating the battery converter. However, this solution is only suitable for low power applications, since these integrated systems do not



(a)

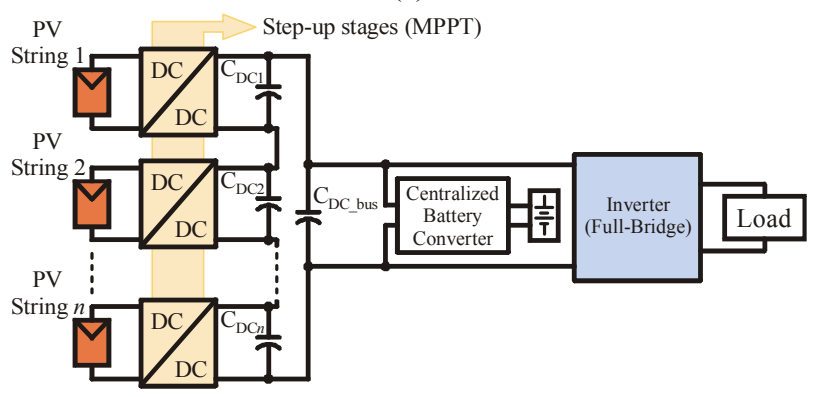

(b)

Fig. 1 - Comparison between the (a) proposed stand-alone PV system and the (b) decentralized stand-alone PV system [9].

consider an appropriated charge/discharge method. Additional details about how the charge/discharge method affects the lifetime of the battery bank are presented section 2-B.

\section{A. The multilevel inverter}

The chosen multilevel topology for the proposed system is composed by cascaded half-bridge cells, where each cell is connected in the output of the first stage of the module [2], [12]-[13], as shown in Fig. 2. The multilevel cells are responsible for producing a specified voltage level, and the series connection of them will generate the desired sinusoidal waveform. This topology presents modular characteristic, simple control and high efficiency due to the low frequency operation possibility. However, as can be seen in Fig. 2, only the multilevel cells cannot produce an ac voltage waveform. Thus, a full-bridge inverter is necessary at the output of the cascaded multilevel cells, which operates in the output frequency $(50$ or $60 \mathrm{~Hz})$.

Furthermore, low voltage semiconductor switches can be employed in the multilevel cells $\left(\mathrm{S}_{\mathrm{m}_{-} 1 \mathrm{a}}, \mathrm{S}_{\mathrm{m}_{-} 1 \mathrm{~b}}, \ldots, \mathrm{S}_{\mathrm{m}_{-} n \mathrm{a}}\right.$ and $\mathrm{S}_{\mathrm{m}_{-} \mathrm{b}}$ ), depending on the number of levels implemented. On the other hand, the full-bridge inverter switches $\left(\mathrm{S}_{\mathrm{fb} \_}, \mathrm{S}_{\mathrm{fb} \_2}, \mathrm{~S}_{\mathrm{fb} \_3}\right.$, and $\left.\mathrm{S}_{\mathrm{fb} \_4}\right)$ process all power of

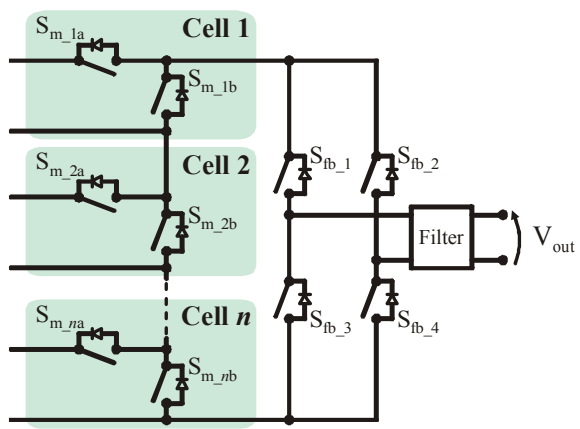

Fig. 2 - Chosen multilevel topology. 
the PV system and can be implemented with lowfrequency semiconductor devices, such as thyristors.

The proposed structure can be employed in medium power applications (one up to tens of kilowatts), and for high power applications it can be extended to a three-phase structure. It can be also observed that the multilevel cells can operate in low, medium or high frequency depending on the selected modulation strategy. There are also the symmetric and asymmetric design methods, which can improve the waveform distortion level by increasing the number of levels of the load voltage.

It is important to notice that only the symmetric design method, where each level is calculated by (1), is considered in this paper. Yet, the multilevel cells will operate in medium frequency employing the phase-shift modulation strategy, making possible to minimize the total harmonic distortion (THD) of the synthesized voltage waveform [14].

The phase-shift modulation employs ( $m-1) / 2$ carriers, where $m$ is the number of levels, shifted by a phase angle defined by (2).

$$
\theta_{d}=\frac{360^{\circ}}{(m-1) / 2}
$$

\section{B. The battery converter}

The battery charger/discharger system is composed by a bidirectional (BD) converter with a " $\mathrm{T}$ " passive filter, as shown in Fig. 3. This converter operates in two modes: (i) buck mode, charging the batteries; and (ii) boost mode, discharging the batteries. This converter is also responsible for the dc bus voltage regulation of each multilevel cell, according to the power produced and demand.

The selection of this topology was deeply discussed and analyzed in [15], as well as its operation modes, project methodology and control strategy. It was verified that implementing an appropriate charge/discharge method, as the UI method (one current level, one voltage level), the durability of the Valve Regulated Lead Acid (VRLA) batteries is extended. Such improvement is significant considering the maintenance costs of a stand-alone PV system.

The proposed structure, as can be seen in Fig. 1(a), has a bidirectional converter for each multilevel cell, representing an increase on the component count. However, as demonstrated in [16], decentralized battery systems can optimize the battery lifetime. In addition, the initial cost of the PV system can offset the impact on the cost of the PV system caused by the increase of converters. Another advantage of the DBC over the $\mathrm{CBC}$ system is the possibility of employing batteries with different capacities and autonomies. This feature introduces an additional degree of freedom on the project of the standalone system (power and voltage levels processed by each module, multilevel inverter configuration - symmetric, asymmetric or hybrid topologies - and modulation strategy. Considering these different possibilities, there is a great flexibility in the power generation system design.



Fig. 3 - Bi-directional battery charger/discharger converter.

\section{Operation modes}

The operation modes of the proposed structure aim the power balance under any conditions of the system, and they are similar to the operation modes of the structure described in [9]. However, there are special conditions with more than one possibility. Among these particular cases, it can be quoted the condition where there are not enough power generated by the PV panels and the batteries are fully discharged. In this case, the energy distribution system could employ a management of priority loads, reducing the overall demand, or else shutting down the entire system. These special cases will not be analyzed in this paper.

The operation modes of a generalized module " $n$ " (extended to each module of the system) are illustrated in Fig. 4 and will be discussed as follows.

- $\quad$ Mode 1 (Fig. 4(a))

The power generated by the PV panels is equal to the power demanded by the load. The bi-directional converter does not operate.

- $\quad$ Mode 2 (Fig. 4(b))

The power generated by the PV panels is lower than the power demanded by the load. Thus, the bi-directional converter discharges the battery bank (boost mode), regulating the dc bus at the specified level.

- $\quad$ Mode 3 (Fig. 4(c))

The power generated by the PV panels is higher than the power demanded by the load. In order to regulate the dc bus, the bi-directional converter charges the battery bank (buck mode) of the correspondent module.

- $\quad$ Mode 4 (Fig. 4(d))

The power generated by the PV panels is higher than the power demanded by the load and the batteries are fully charged. Therefore, the dc-dc input converter turns-off the MPPT mode and sets the regulation mode $(\mathrm{RM})$, being responsible for the voltage level regulation on the dc bus. Then, the power generated is equal to the power demanded by the load.

\section{Control of the structure}

In order to guarantee that the maximum power will be extracted from the PV panels, a MPPT algorithm must be employed. Therefore, among the several algorithms proposed in literature [17]-[18], the Perturb \& Observe (P\&O) algorithm was selected, which varies the point of operation by means of duty cycle of each dc-dc input converter. 




(a)

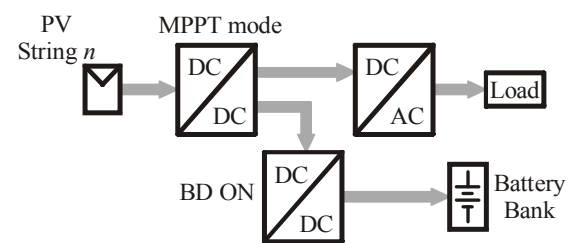

(c)

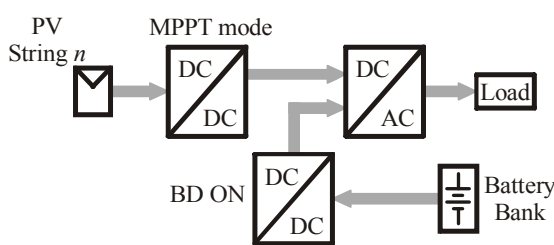

(b)

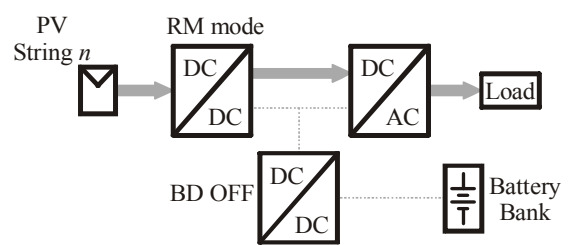

(d)

Fig. 4 - Operation modes of the proposed system: (a) mode 1, (b) mode 2, (c) mode 3 and (d) mode 4.

Additionally, dc bus level of each module must be regulated. The regulation of the dc bus can be managed by the dc-dc input converter (modes 1 and 4), or by the bidirectional converter (modes 2 and 3). For the input converters in regulation mode, a simple voltage loop guarantees the voltage regulation.

However, if the bi-directional converters are performing the dc bus regulation, a current loop must be also implemented on the control system in order to guarantee a charge/discharge current into the batteries approximately constant. The control system of the bi-directional converter is depicted in Fig. 5, where $G_{i d}(s)$ is the transfer function that relates the current through the batteries $i_{b a t}$ to dutycycle of the converter $d, G_{v i}(s)$ is the transfer function that relates the dc bus voltage $v_{b u s}$ to $i_{b a t}$, and $C_{i d}(s)$ and $C_{v i}(s)$ are the correspondent controllers. The gain of the current and voltage sensors are $H_{i}$ and $H_{v}$, respectively.

\section{Simulation Results}

In order to validate the proposed topology, the PV system was simulated with three strings. Step-up dc-dc converters (boost) implement the first stage, tracking the maximum power point (MPP) of the panels. Connected at the output of the first stage, the multilevel inverter generates a seven-level waveform. In this stage, a phaseshift modulation was implemented, reducing the total harmonic distortion of the output signal. The simulation parameters are summarized in Table 1.

First, it was simulated a string composed by three PV panels of $130 \mathrm{~W}$, resulting in $1170 \mathrm{~W}$ of total installed power. Initially, each PV string is producing $390 \mathrm{~W}$ at a radiation of $1000 \mathrm{~W} / \mathrm{m}^{2}$. In this case, there is excess of power produced and the batteries are not fully charged (mode 3). Thus, the bi-directional converters should charge the batteries (positive current on the batteries) regulating the energy balancing of the system. The dc bus voltage of each

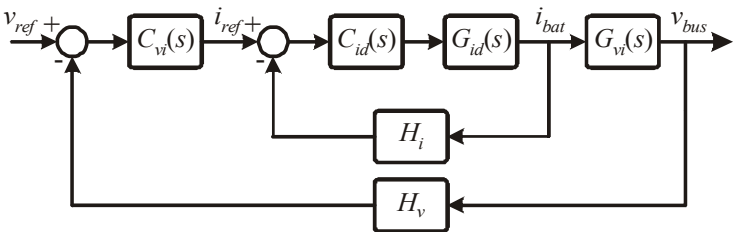

Fig. 5 - Control system of the bi-directional converter. cell is regulated at $133 \mathrm{~V}\left(V_{m}=400 \mathrm{~V}, n_{\text {str }}=3\right)$ and the modulation index is 0.77 , resulting in a $220 \mathrm{~V}_{\text {rms }}$ sinusoidal waveform at the output of the multilevel inverter.

In Fig. 6(a) it is plotted the power produced by the string 2 . Causing a partial shading only on the PV string 2 at 0.6 seconds, when the radiation is reduced from $1000 \mathrm{~W} / \mathrm{m}^{2}$ to $500 \mathrm{~W} / \mathrm{m}^{2}$, the power produced on the string decreases. Consequently, the dc bus level decreases due to the lack of power, illustrated in the Fig. 6(b). This way, the control of the bi-directional converter interrupts the charge process of the batteries, and begins the discharge procedure (negative current on the batteries) in order to regulate the dc bus of the cell 2, as can be observed in Fig. 6(c). The output multilevel waveform (without filter) is depicted in Fig. 6(d), presenting a THD of $0.15 \%$. It can be noticed a small reduction on the amplitude due to the perturbation event, although this transient could be compensated by operating the multilevel inverter in closed loop control.

Fig. 7 illustrates the behavior of the system during a change of operation mode. Before 0.5 second, the system is in mode 3, where the batteries are charging (Fig. 7(a)). After 0.5 second it was verified that the batteries have reached full charge. Then, the system goes to the regulation mode (mode 4). It can be noticed the drop of the batteries current down to zero, at the same time the boost converter starts the regulation of the dc bus voltage (Fig. 7(b)). Since there is excess of power, the PV panels do not produce the maximum power no longer, as can be seen in Fig. 7(c).

Table 1 - Simulation parameters.

\begin{tabular}{|c|c|}
\hline Number of strings & 3 \\
\hline Number of PV panels per string & 3 \\
\hline Total installed power & $1170 \mathrm{~W}$ \\
\hline $\begin{array}{c}\text { Boost and bi-directional switching } \\
\text { frequency }\end{array}$ & $40 \mathrm{kHz}$ \\
\hline $\begin{array}{c}\text { Multilevel cells switching } \\
\text { frequency }\end{array}$ & $10 \mathrm{kHz}$ \\
\hline DC Bus voltage & $133 \mathrm{~V}$ \\
\hline Modulation index & 0.77 \\
\hline Output voltage / frequency & $220 \mathrm{~V}_{\mathrm{rms}} / 60 \mathrm{~Hz}$ \\
\hline Number of batteries per string & 5 \\
\hline
\end{tabular}




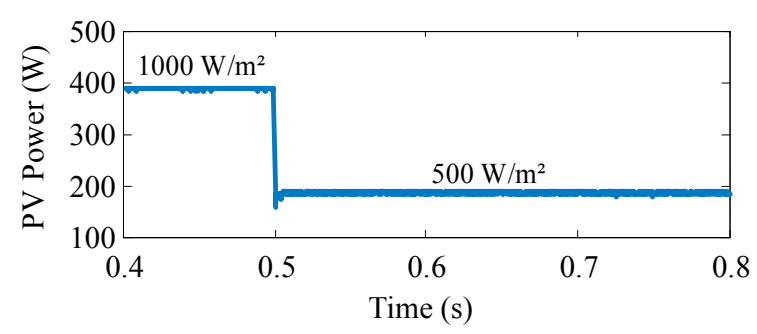

(a)

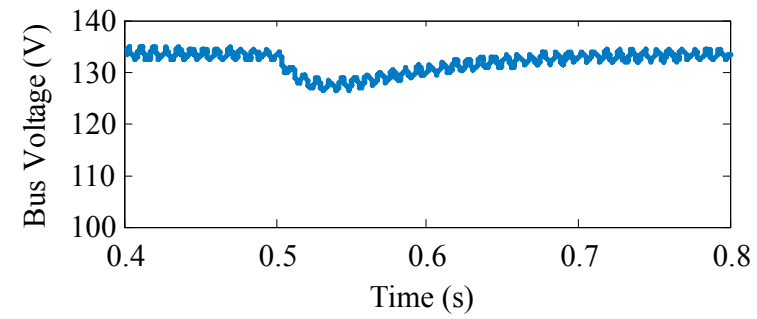

(b)

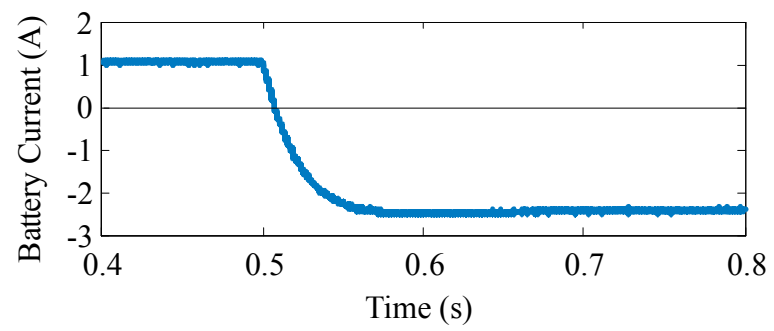

(c)

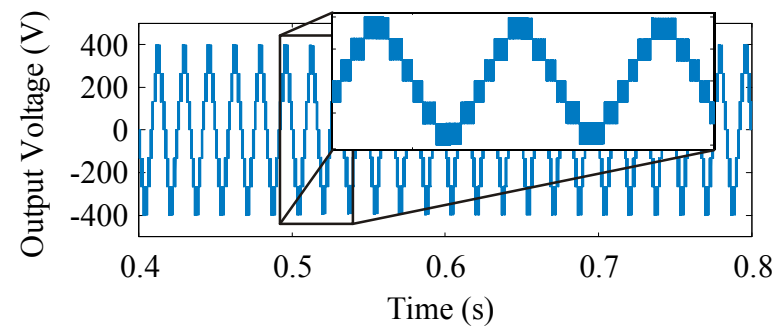

(d)

Fig. 6 - Simulation results of string 2: (a) power produced by the PV panels, (b) dc bus voltage, (c) battery current and (d) output voltage without filter.

\section{Conclusion}

This paper proposed a stand-alone PV system with a multilevel inverter in the dc-ac stage for medium power applications. The multilevel inverter presents attractive advantages when compared to conventional inverters, such as low harmonic distortion of the output waveform and employment of low voltage semiconductor devices.

The structure is also composed by converters dedicated to small sets of batteries, called decentralized battery system. Moreover, several design possibilities can be achieved aiming the most efficient and low cost PV system project. It was also considered an appropriated charge/discharge method for the batteries aiming to minimize the maintenance costs of the batteries in stand-alone systems.

By means of simulation results, the effectivity of the proposed structure, as well as its control system were verified.

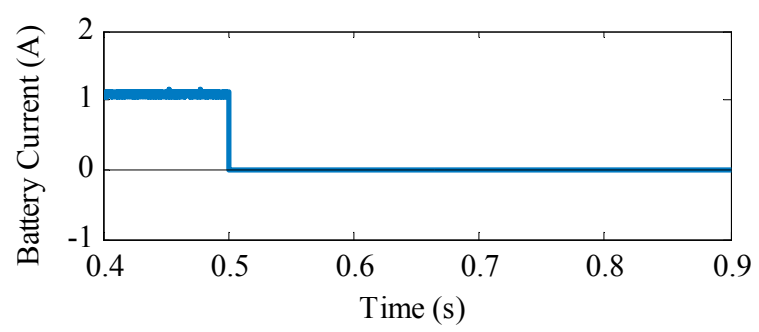

(a)

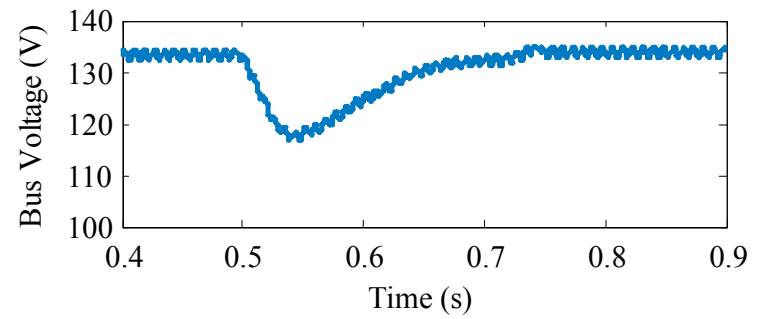

(b)

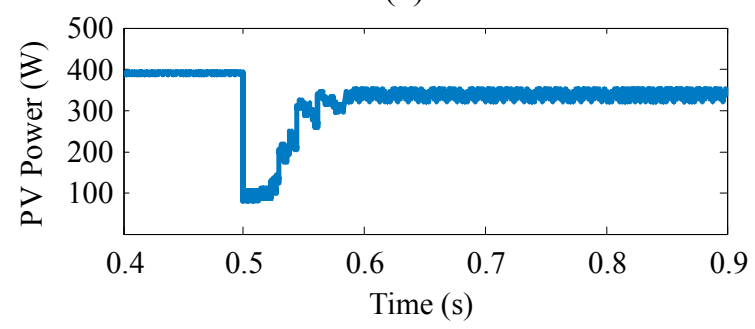

(c)

Fig. 7 - Transition of mode 3 to mode 4: (a) battery current, (b) dc bus voltage and (c) power produced by the $\mathrm{PV}$ panels.

\section{Acknowledgement}

The authors would like to express their gratitude to "Coordenação de Aperfeiçoamento de Pessoal de Nível Superior - CAPES" and "Conselho Nacional de Desenvolvimento Científico e Tecnológico - CNPQ" for financial support.

\section{References}

[1] "Key world energy statistics - 2009", International Energy Agency (IEA), 2009. Available at: http://www.iea.org.

[2] F. Kininger, "Photovoltaic systems technology". Kassel, Germany: Universität Kassel, Institut für Rationelle Energiewandlung, 2003. Available at: www.uni-kassel.de/re.

[3] M. Liserre, T. Sauter, J.Y. Hung, "Future energy systems: integrating renewable energy sources into the smart power grid through industrial electronics," IEEE Industrial Electronics Magazine, vol.4, no. 1, pp. 18-37, Mar. 2010.

[4] "Global Market Outlook for Photovoltaics Until 2014", European Photovoltaic Industry Association (EPIA). Available at: http://www.epia.org.

[5] "Energy poverty: how to make modern energy access universal", World Energy Outlook 2010, International Energy Agency (IEA). Available at: http://www.iea.org.

[6] "Management of storage batteries used in stand-alone photovoltaic power systems - report, IEA PVPS T310:2002”, International Energy Agency (IEA), 2002. Available at: $\mathrm{http}: / / \mathrm{www}$.iea.org.

[7] M. Meinhardt and G. Cramer, "Past, present and future of grid connected photovoltaic- and hybrid-power-systems," in Proc. IEEE-PES Summer Meeting, vol. 2, 2000, pp. $1283-1288$. 
[8] M. Meinhardt and G. Cramer, "Multi-string-converter: The next step in evolution of string-converter technology," in Proc. 9th Eur. Power Electronics and Applications Conf., 2001, CD-ROM.

[9] D.B. Candido, J.R.R. Zientarski, R.C. Beltrame, J.R. Pinheiro, H.L. Hey, "Implementation of a stand-alone photovoltaic system based on decentralized dc-dc converters," in Proc. Brazilian Power Electronics Conference, Sept. - Oct. 2009, pp. 174-180.

[10] Du Yang, D.D.-C. Lu, "Analysis of a battery-integrated boost converter for module-based series connected photovoltaic system," in Proc. International Power Electronics Conference, June 2010, pp.694-698,

[11] R. Gules, J. De Pellegrin Pacheco, H.L. Hey, J. Imhoff, "A maximum power point tracking system with parallel connection for PV stand-alone applications," IEEE Trans. on Industrial Electronics, vol. 55, no. 7, pp. 2674-2683, July 2008.

[12] J. Schmid et al., "Inverter for converting a direct voltage into an alternating voltage," U.S. Patent 4775 923, Oct. 4, 1988.

[13] M. Calais, V.G. Agelidis, "Multilevel converters for single-phase grid connected photovoltaic systems-an overview," in Proc. IEEE International Symposium on Industrial Electronics, July 1998, vol. 1, pp. 224-229.
[14] C. Rech, H.A. Gründling, H.L. Hey, H. Pinheiro, and J.R Pinheiro, "A generalized design methodology for hybrid multilevel inverters," in Proc. IEEE Conference of the Industrial Electroncs Society, Nov. 2002, pp. 834-839.

[15] L. Schuch, C. Rech, H. L. Hey, H. Pinheiro, H. A. Gründling, J. R. Pinheiro "Analysis and design of a highperformance bi-directional PWM converter for DC bus and battery bank interface," in Proc. Brazilian Power Electronics Conference, 2001, pp. 532-537.

[16] C.-S. Moo, K.-S. Ng, J.-S. Hu, "Operation of battery power modules with series output," in Proc. IEEE International Conference on Industrial Technology, Feb. 2009, pp. 1-6.

[17] D.P Hohm, M.E. Ropp, "Comparative study of maximum power point tracking algorithms using an experimental, programmable, maximum power point tracking test bed," in Proc. 28th IEEE Photovoltaic Specialists Conf., 2000, pp.1699-1702.

[18] T. Esram, P.L. Chapman, "Comparison of Photovoltaic Array Maximum Power Point Tracking Techniques," IEEE Trans. on Energy Conversion, vol.22, no. 2, pp.439-449, June 2007. 